\title{
Predicting the cell death responsiveness and sensitization of glioma cells to TRAIL and temozolomide
}

\author{
Birgit C. Weyhenmeyer ${ }^{1,2, *}$, Janis Noonan ${ }^{1,2, *}$, Maximilian L. Würstle ${ }^{1,2}$, Frank A.

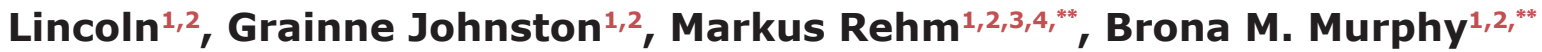 \\ ${ }^{1}$ Department of Physiology \& Medical Physics, Royal College of Surgeons in Ireland, Dublin, Ireland \\ ${ }^{2}$ Centre for Systems Medicine, Royal College of Surgeons in Ireland, Dublin, Ireland \\ ${ }^{3}$ Institute of Cell Biology and Immunology, Faculty of Energy-, Process- and Biotechnology, University of Stuttgart, Stuttgart, \\ Germany \\ ${ }^{4}$ Stuttgart Research Center Systems Biology, University of Stuttgart, Stuttgart, Germany \\ *These authors have contributed equally to this work \\ *** These authors share senior authorship \\ Correspondence to: Markus Rehm, email: mrehm@rcsi.ie \\ Brona M. Murphy, email: bronamurphy@rcsi.ie \\ Keywords: glioblastoma, TRAIL, temozolomide, apoptosis, systems biology \\ Received: December 08, $2015 \quad$ Accepted: July 18, $2016 \quad$ Published: August 01, 2016
}

\section{ABSTRACT}

Genotoxic chemotherapy with temozolomide (TMZ) is a mainstay of treatment for glioblastoma (GBM); however, at best, TMZ provides only modest survival benefit to a subset of patients. Recent insight into the heterogeneous nature of GBM suggests a more personalized approach to treatment may be necessary to overcome cancer drug resistance and improve patient care. These include novel therapies that can be used both alone and with TMZ to selectively reactivate apoptosis within malignant cells. For this approach to work, reliable molecular signatures that can accurately predict treatment responsiveness need to be identified first. Here, we describe the first proof-of-principle study that merges quantitative protein-based analysis of apoptosis signaling networks with data- and knowledge-driven mathematical systems modeling to predict treatment responsiveness of GBM cell lines to various apoptosisinducing stimuli. These include monotherapies with TMZ and TRAIL, which activate the intrinsic and extrinsic apoptosis pathways, respectively, as well as combination therapies of TMZ+TRAIL. We also successfully employed this approach to predict whether individual GBM cell lines could be sensitized to TMZ or TRAIL via the selective targeting of $\mathrm{Bcl}-2 / \mathrm{Bcl}-\mathrm{xL}$ proteins with $\mathrm{ABT}-737$. Our findings suggest that systems biology-based approaches could assist in personalizing treatment decisions in GBM to optimize cell death induction.

\section{INTRODUCTION}

Glioblastoma (GBM), the most common form of primary brain tumor in humans, is typically aggressive, highly infiltrative, and resistant to conventional therapy. Despite improvements in surgical technique and the addition of temozolomide (TMZ) to the armamentarium, patient median survival remains dismal at 14.6 months, with most experiencing tumor relapse within 7 months of treatment onset [1] and a large proportion gaining no survival advantage to TMZ therapy at all $[2,3]$. When successful, this oral alkylating drug induces glioma cell death by causing DNA double strand breaks that eventually lead to growth arrest and activation of cellular apoptosis [4].

To date, the only significant prognostic marker of GBM patient response to TMZ is promoter methylation of the gene encoding for MGMT [5, 6]; specifically, promoter methylation has been identified as a feature of favorable outcome in patients undergoing TMZ therapy for both newly diagnosed GBM and recurrent disease [7]. In the elderly sub-population of patients, $M G M T$ testing is now recommended for routine clinical decision making with regards to stratification of therapy; this follows the results 
of two phase 3 clinical trials that clearly demonstrate 'unmethylated' patients benefit more from radiotherapy alone while 'methylated' patients benefit more from TMZ chemotherapy alone [8,9]. In the non-elderly sub-population of GBM patients, however, discordant responses between 'methylated' and 'unmethylated' subgroups of patients exist, indicating that the treatment decision to use TMZ in these patients should not be based on this biomarker alone. Nevertheless, MGMT testing has become commonplace for patient selection within clinical trials [6] [10-13] and is frequently requested as a prognostic biomarker during patient clinical workup [14].

Irrespective of patient responsiveness to TMZ, the dismal prognosis associated with GBM makes it clear that other therapeutic strategies are required, both as stand-alone treatment options and as sensitizing therapies that can be combined with TMZ to overcome current treatment resistance. In line with this, due to the extremely heterogeneous nature of these tumors $[15,16]$, it is becoming increasingly evident that such treatment strategies ought to be individualized and tailored to the needs of each GBM patient. Recent efforts in personalizing anti-cancer treatments have focused on therapies that selectively reactivate apoptosis within malignant cells, such as those that promote apoptosis via the Bcl-2 family of regulatory proteins and those that act by binding to death receptors expressed on the surface of the cell.

Tumor necrosis factor-related apoptosis-inducing ligand (TRAIL), the natural ligand for the apoptotic receptors, DR4 and DR5, is one anti-cancer therapy that has been gaining momentum in recent years $[17$, 18]. Using extrinsic agents like TRAIL has two putative advantages over intrinsic agents: firstly, TRAIL can trigger apoptosis independently of p53, which is commonly mutated in primary $(28 \%)$ and secondary $(65 \%)$ GBM patients [19], contributing, in part, to TMZ resistance [20]; and secondly, TRAIL can kill cancer cells without conferring significant toxicity to normal cells $[21,22]$. Several TRAIL-based therapies, including the human recombinant TRAIL ligand (dulanermin), which targets both DR4 and DR5, and agonistic antibodies against DR4 (mapatumumab) and DR5 (drozitumab, lexatumumab, tigatuzumab, LBY-135, and conatumumab) have been assessed within clinical trials [17, 23]. Unfortunately, while these agents are reportedly well tolerated in patients, both alone and in combination with standard therapies, only isolated responses have been observed. It should be noted, however, that these trials involved no degree of patient pre-selection and thus may not reflect a true clinical evaluation of TRAIL-based therapies, which might be efficacious but only for a subset of patients.

With regards to GBM, most glioma cells are resistant to TRAIL monotherapy, although several promising combination treatments to overcome this resistance have been described [24-28]. Particularly encouraging in vitro and in vivo findings come from the combination of TRAIL and TMZ, which evoke concomitant stimulation of the intrinsic and extrinsic apoptotic pathways [29-31]. Used together, these agents should, in theory, enhance both the likelihood of apoptosis induction as well as the strength of the apoptotic signal. TMZ might also play the role of TRAIL 'sensitizer', overcoming resistance by up-regulating the expression of death receptors, leading in turn to substantial caspase activation $[29,30]$. Other mechanisms of TRAIL and TMZ resistance are shared, such as an up-regulation of anti-apoptotic and down-regulation of pro-apoptotic Bcl-2 proteins and an over-expression of inhibitor of apoptosis (IAP) proteins [23, 32].

Small molecules that antagonize pro-survival Bcl-2 proteins, namely $\mathrm{BH} 3$ mimetics, are currently under preclinical and clinical evaluation as single agent anti-cancer therapies and as sensitizers to apoptosis-inducing drugs $[33,34]$. One of the most advanced and well characterized small molecule inhibitors is the BH3 mimetic, ABT-737, which predominantly binds to $\mathrm{Bcl}-2$ and $\mathrm{Bcl}-\mathrm{xL}$ to induce or sensitize cells to apoptosis through the intrinsic pathway. As a single agent, ABT-737 has shown anti-tumor activity in GBM cells in vitro [35], while in concert with TRAIL, it has demonstrated efficacious results in an in vivo model of GBM [27]. Recently, ABT-737 has also been shown to sensitize gliomas cells to TMZ-induced apoptosis [36].

Despite these promising studies, molecular marker signatures that could facilitate reliable predictions on the responsiveness of individual GBM cases to TMZ and TRAIL alone or in combination currently do not exist. Likewise, tools to predict ABT-737-based sensitization of GBM cells to TMZ or TRAIL have not yet been developed. Here, we addressed these problems in a first pre-clinical proof-of-principle study in which we merged quantitative experimental studies with dataand knowledge-driven mathematical system modeling to predict treatment responsiveness of GBM cell lines.

\section{RESULTS}

\section{Defining and parameterizing functional groups of cell death regulators for knowledge- and data-driven systems modeling}

We previously demonstrated that a knowledge- and data-driven mathematical modeling approach is capable of generating reliable predictions of melanoma cell line responsiveness to both TRAIL- and genotoxic druginduced cell death, outperforming classical statistical procedures [37]. As part of this approach, biological pathway information on linear and non-linear interplay between cell death regulatory proteins is integrated into data obtained from quantitative measurements of these proteins. This is achieved by defining "functional groups (FGs)" in which multiple proteins are related to each other by simple arithmetic rules (sums, products, or ratios of a small number of proteins), multivariate statistical analysis, 
and the application of pattern recognition algorithms [3739]. To apply this approach to the TRAIL- and TMZ-based treatments in GBM, the relevant signaling pathways and the respective FGs first needed to be defined.

The apoptosis pathway activated by TRAIL is well characterized and depicted in Figure 1A. Briefly, TRAIL binds to death receptors, DR4 and DR5, on the surface of the cell, resulting in the recruitment of the adaptor protein, Fas-associated death domain (FADD), through death effector domain (DED) interactions. FADD, in turn, recruits pro-caspase-8, pro-caspase-10 and/or cellularFLIP (cFLIP), thereby forming the multi-protein deathinducing signaling complex (DISC) [40]. Pro-caspase-8 recruitment to the DISC results in its autocatalytic processing to the active caspase- 8 enzyme; however, c-FLIP proteins can inhibit this process. If activated, caspase-8 can subsequently go on to activate effector caspases such as caspase-3 to execute the extrinsic apoptotic pathway [41]. Alternatively, caspase-8 can activate the intrinsic pathway via cleavage of the BH3only protein, Bid. The truncated active form of Bid, tBid, engages with Bax or Bak to induce mitochondrial outer membrane permeabilisation (MOMP) and release of cytochrome $c$ and second mitochondria-derived activator of caspases (SMAC) into the cytosol [42]. This mitochondrial pathway of apoptosis, which involves additional BH3-only proteins, such as Bim, Puma and Noxa $[43,44]$, is also the entry point for cell death signals triggered by chemotherapeutics like TMZ [4, 45-48]. The function of $\mathrm{BH} 3$-only proteins and activated Bax or Bak is antagonized by the anti-apoptotic Bcl-2 family proteins, Bcl-2, Bcl-xL and Mcl-1. Once in the cytosol, cytochrome $c$ interacts with apoptotic protease activating factor 1 (Apaf-1) to form the heptameric backbone of the apoptosome complex, which in turn recruits and activates caspase-9 [49]. At the same time, SMAC neutralizes the caspase-inhibitory function of X-linked inhibitor of apoptosis protein (XIAP) to assist in the ultimate activation of effector caspases like caspase-3 [50].

We used this knowledge of pathway topology to group the above-mentioned proteins into FGs based on their relationships within the signaling network (Figure 1B). For example, we grouped together Bcl-2, Bcl-xL and Mcl-1 by adding their $\mathrm{nM}$ amounts since these represent functionally redundant antagonists of Bax and Bak. Similarly, we grouped together Bax and Bak since they form the mitochondrial pores leading to MOMP. The BH3-only proteins, Bid, Bim, Puma, and Noxa, were kept as separate variables for a number of reasons. Firstly, Bid plays an essential role in driving the activation of the mitochondrial pathway of apoptosis, specifically in response to extrinsic pathway stimulation; therefore, functionally, Bid is largely separate from the other BH3-only proteins. Secondly, the respective relevance and individual importance of Bim, Puma and Noxa in regulating the TMZ-induced intrinsic pathway of apoptosis is still a matter of debate [51]. Furthermore, since these BH3-only proteins may need to be transcriptionally induced or posttranslationally modified in response to TMZ, either alone or in combinations, the relevance of their baseline expression levels with regards to determining cell death responsiveness is not yet clear [51-53]. It is also possible that these proteins functionally differ in their capacity to activate/antagonize pro- and anti-apoptotic Bcl-2 family proteins [54, 55]. Thus, keeping these proteins as separate variables allowed us to better understand their respective impact on the model's performance. Of note, in the subsequent results we did not observe a notable improvement in model performance when merging these proteins into one FG (not shown). To define the caspase-9-activating apoptosome complex, we multiplied the protein concentrations of Apaf-1 and caspase-9; this multiplication ensured that the value for this group approached zero when either Apaf-1 or caspase-9 expression was low or absent. We applied the same reasoning to the grouping of DR4, DR5 and FADD; this group represented the DISC. FGs of apoptotic caspases and their antagonists (cFLIP and caspase-8; XIAP and caspase-3) were defined as ratios. SMAC remained as a single protein and accordingly was kept as an individual variable.

To parameterize these $11 \mathrm{FGs}$ with protein data, we carried out quantitative flow cytometry to determine the cell surface expression of death receptors 4 and 5 as well as quantitative immunoblotting to determine the relative protein expression of the other 17 key players of the apoptotic pathways activated by TRAIL and TMZ (Supplementary Table S1). An overview, based on a total of 627 quantifications in 11 cell lines, is provided in Figure 1C. The resulting quantities for the FGs are provided in Supplementary Table S2. The cell lines chosen for this study included both commercially available cell lines, A172, U87, U251, U343, and U373 and a cohort of lines derived from patient GBMs, including both primary (MZ18, MZ51, MZ294, MZ327) and recurrent (MZ256, MZ304) tumors. All of the commercially available lines expressed a methylated $M G M T$ promoter whilst among the patient derived cell lines, MZ18, MZ51 and MZ294 expressed a methylated promoter and MZ304, MZ256 and MZ327 expressed an unmethylated promoter. Of note, statistical analysis comparing the relative expression of apoptotic proteins, as listed in Supplementary Table S1, in "methylated" versus "unmethylated" cell lines revealed no relationship between protein expression profiles, methylation status and response to treatment (not shown).

\section{Functional groups of apoptosis regulators in GBM cell lines can be associated with cell death responsiveness to TMZ and TRAIL monotherapy}

Following the parameterization of the FGs, these data were analyzed to determine if any relationship existed between FG values and the responsiveness of each cell line to TMZ or TRAIL. First, we applied a principal component analysis (PCA) to the FG data. This statistical procedure 
allowed us to accumulate the variance observed in the 11 FGs in the 11 cell lines in a lower number of independent dimensions, referred to as principal components (PCs) (Figure 2A). The variance explained by the respective PCs indicates that the first 4 PCs needed to be retained for the subsequent analyses to capture approximately $70 \%$ of the data variance of the original data set, and all subsequent analyses were therefore conducted in this 4D PC space. Each PC is defined by distinct contributions of the different FGs, according to specific weighting coefficients for the FGs (Figure 2B, Supplementary Table S3).

For visualization purposes, the cell-line specific values of the FGs, multiplied with the FG-specific coefficients in the first three $3 \mathrm{PCs}$, allowed us to position the 11 GBM cell lines within a three dimensional PC space (Figure 2C). The position of the individual cell lines in the $\mathrm{PC}$ space is therefore associated with their respective individual protein expression profiles. The distribution of the cell lines within the PC space demonstrated that the cell lines did not form spatially separated clusters, indicating a high degree of heterogeneity between the GBM cell lines (Figure 2C). Additional information on this procedure is provided in the methods section and the published literature [37].

Next, we asked whether the PC space, and therefore the protein composition of the apoptosis signaling network, contains information on whether the cell lines are responsive to TMZ or TRAIL. To this end, we first experimentally measured cell viability following TMZ or TRAIL treatment in all cell lines (Figure 2D). Our data showed that the responsiveness of the cell lines to TMZ or TRAIL varied substantially across the panel and also that individual cell lines frequently responded differently to TMZ or TRAIL. Furthermore, we also noted that very few cell lines responded well to these treatments (Figure 2D). Previous work from our group has highlighted that a reduction in cell survival in TMZ responsive cell lines, U251 and U343, correlates with activation of the intrinsic apoptotic cell death pathway, as demonstrated by a significant increase in the number of condensed nuclei and AnnexinV staining, as well as procaspase-3 activation and PARP cleavage; we also showed that such cell death could be suppressed by caspase inhibition with zVAD-fmk and that no such responses were evident in TMZ-resistant cell lines [56]. To confirm that the TRAIL-sensitive cell lines were undergoing apoptosis via the extrinsic pathway, we examined the processing of procaspase- 8 in the TRAIL-sensitive cell line, A172; cleavage of caspase- 8 was clearly detected $24 \mathrm{~h}$ post TRAIL treatment (Supplementary Figure S1A). We also examined the effect of TRAIL treatment on the executioner caspase, caspase-3, and found that TRAIL treatment also led to the cleavage of pro-caspase-3 after $24 \mathrm{~h}$ (Supplementary Figure S1A). Activation of both caspase- 8 and caspase- 3 was prevented by the combined presence of zVAD-fmk and TRAIL (Supplementary Figure S1A). Furthermore, we detected a significant increase in Annexin $V$ positive cells following TRAIL treatment (Supplementary Figure $\mathrm{S} 1 \mathrm{~B}$ ), which was also prevented by zVAD-fmk. None of these events were evident in the TRAIL-resistant cell line, MZ304 (Supplementary Figures S1A, S1B).
A

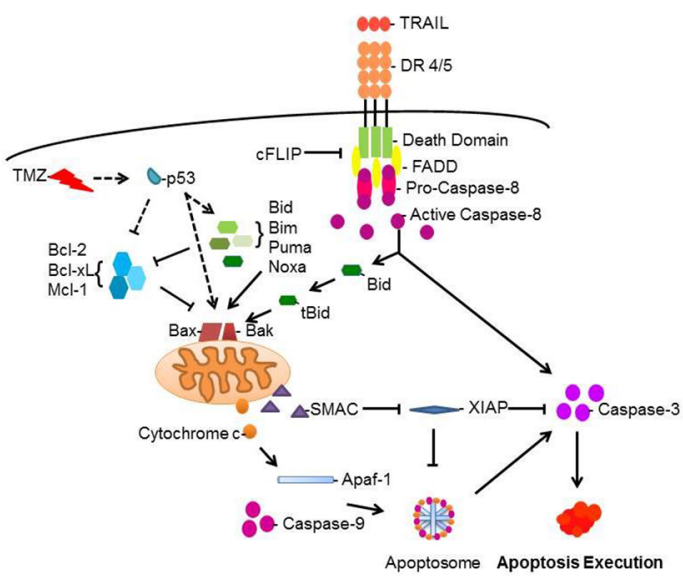

B

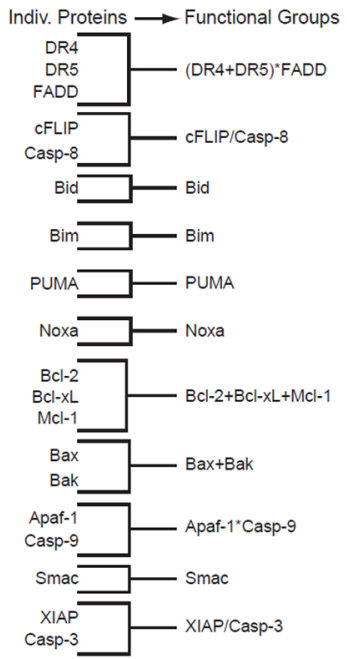

C

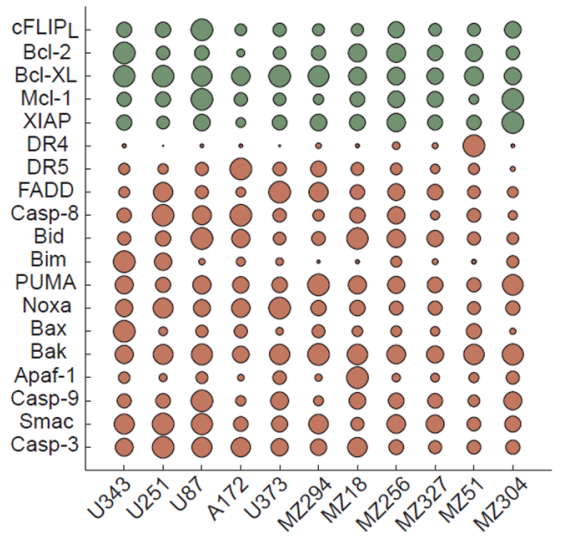

Figure 1: Coding and parameterizing functional groups of apoptosis signaling proteins for knowledge- and datadriven systems modeling. A. Pathway diagram for intrinsic and extrinsic apoptosis pathways elicited by TMZ and TRAIL, respectively. B. Grouping of apoptosis signaling proteins into functional groups by simple arithmetic operations. C. Relative levels of protein expression within the GBM cell line panel. Circles summarize 627 quantifications, while circle sizes are proportional to the protein quantities determined from $n=3$ independent experiments. Green and red indicate anti- and pro-apoptotic proteins, respectively. Protein expression amounts are provided in Supplementary Table S1. The resulting FG values are provided in Supplementary Table S2. 
A

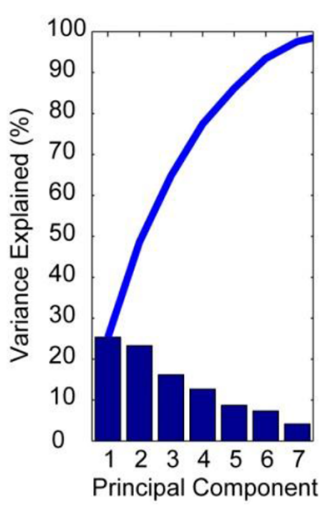

C

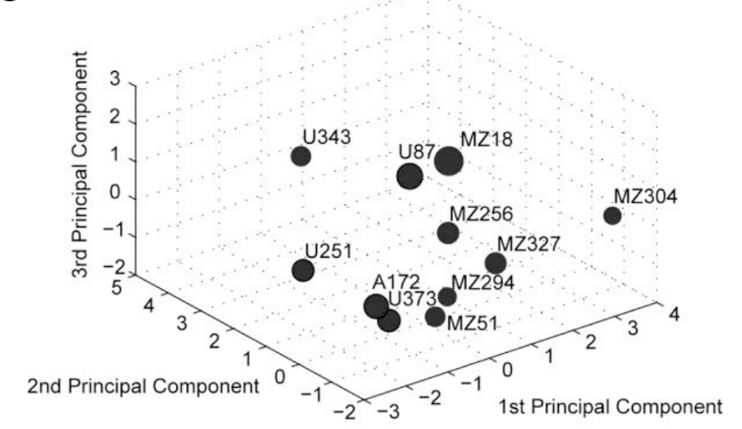

$\mathbf{E}$

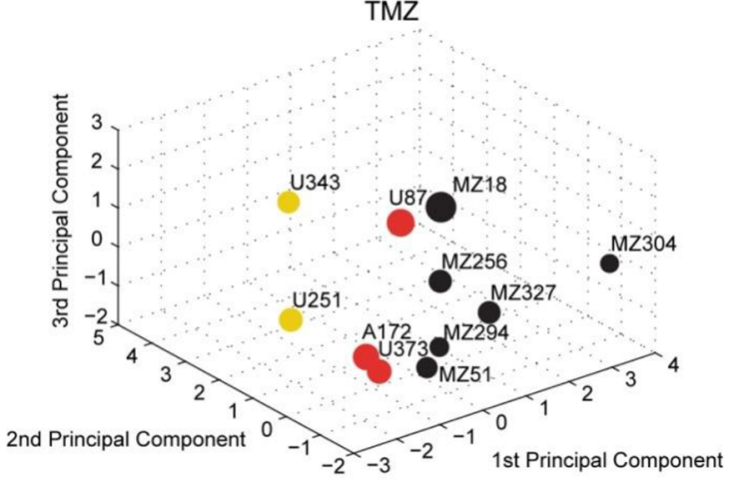

B

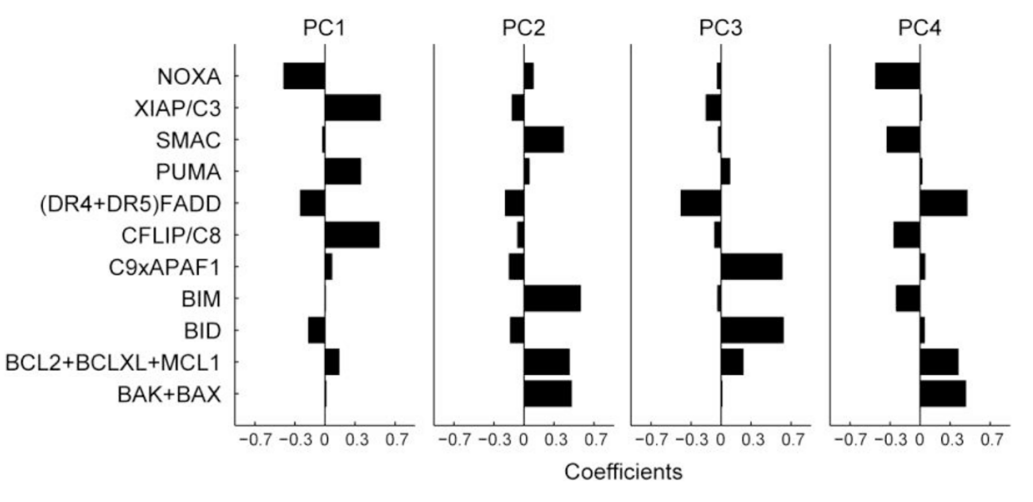

D
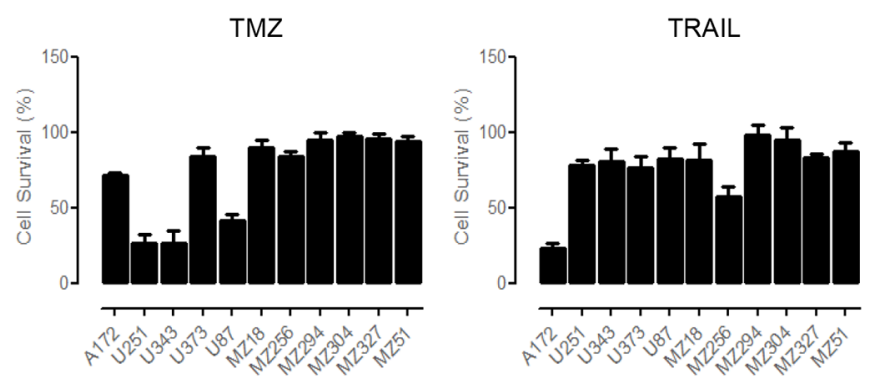

$\mathbf{F}$

TRAIL

\section{G}

\begin{tabular}{c|c|c} 
Drug & $\begin{array}{c}\text { \# Correctly } \\
\text { Classified }\end{array}$ & $\begin{array}{c}\text { \% Correctly } \\
\text { Classified }\end{array}$ \\
\hline TMZ & $11 / 11$ & $100 \%$ \\
TRAIL & $10 / 11$ & $91 \%$
\end{tabular}

Figure 2: Functional groups of cell death regulators highlight an association between protein expression profiles and cell survival following TMZ and TRAIL treatment. A. A principal component analysis (PCA) was applied to the functional groups of the GBM cell line panel. Results are shown as a scree plot. Bar graphs show the contribution of each principal component (PC) toward explaining the data variance. B. Bar graphs show the coefficients for all functional groups in the first four PCs. Coefficient values are provided in Supplementary Table S3. C. Graphical illustration of the distribution of GBM cell lines along the first three PCs. Circle sizes decrease with distance from the observer to aid 3D visualization. D. Cell survival following TMZ and TRAIL monotherapy. Cells were treated with TMZ $(150 \mu \mathrm{M})$ or TRAIL $(100 \mathrm{ng} / \mathrm{ml})$ for $96 \mathrm{~h}$ followed by cell viability measurement. Data show cell survival relative to control values of $100 \%$ (mean \pm SEM from $n=3$ independent experiments). $\mathbf{E}$ and $\mathbf{F}$. Cell lines in the 3D PC space were color coded according to their responsiveness to TMZ and TRAIL, respectively. G. Performance of the response group separation in the 4D PC space by linear discriminant analysis (LDA) is shown by listing the amount of correctly classified cell lines. 
Subsequently, cell lines were defined treatmentspecifically as highly responsive (up to $30 \%$ survival), low responsive (30-80\% survival) or resistant ( $>80 \%$ survival). According to the definition of response classes, the cell lines positioned in the PC space were color coded (Figure 2E, 2F). Interestingly, it appeared that within the $3 \mathrm{D}$ space, resistant cell lines seemed to be spatially separated from cell lines with higher responsiveness (Figure 2E, 2F). While visually this pattern was obvious, we tested whether this separation could likewise be achieved objectively by using linear discriminant analysis (LDA), an algorithm that aims to separate the responsiveness groups by hyperplanes in the 4D PC space. The separation of the response groups by this approach was highly accurate, with all cell lines correctly classified

A
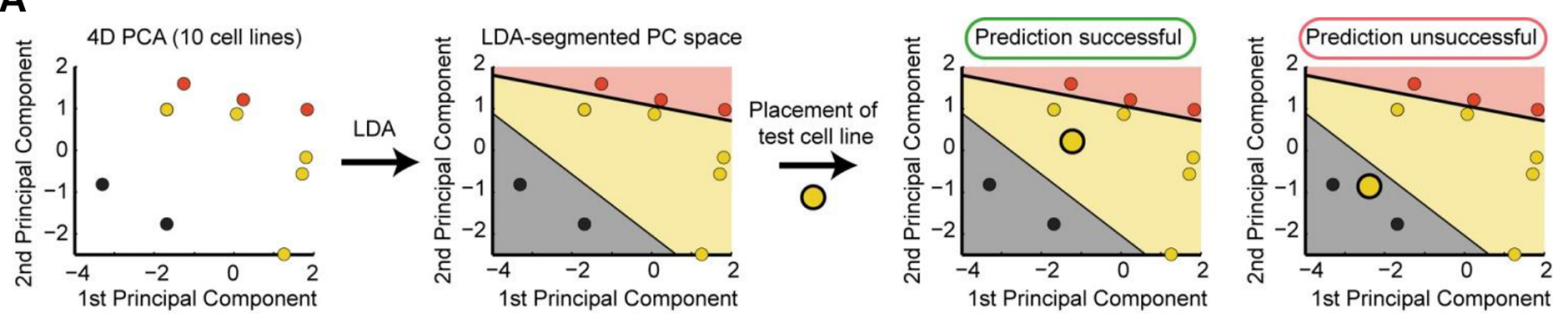

B
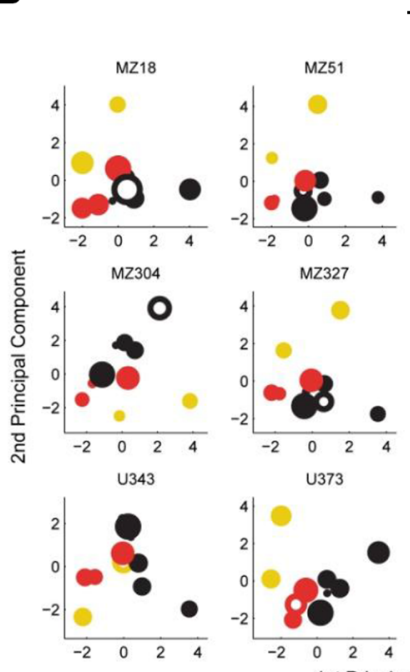

TMZ

C
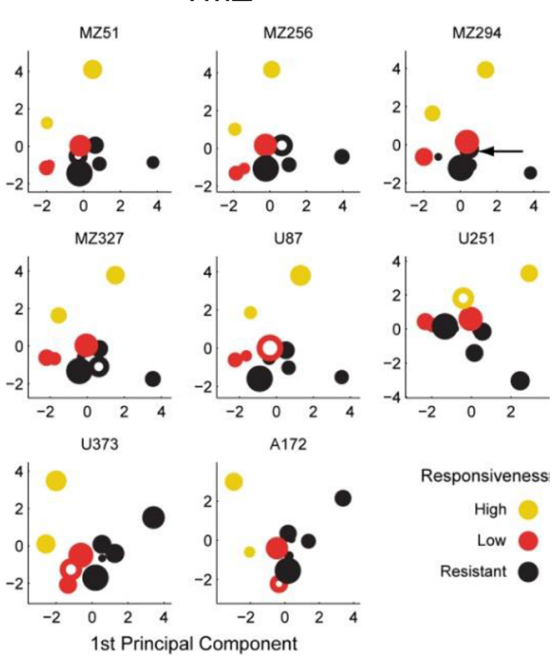

Responsiveness
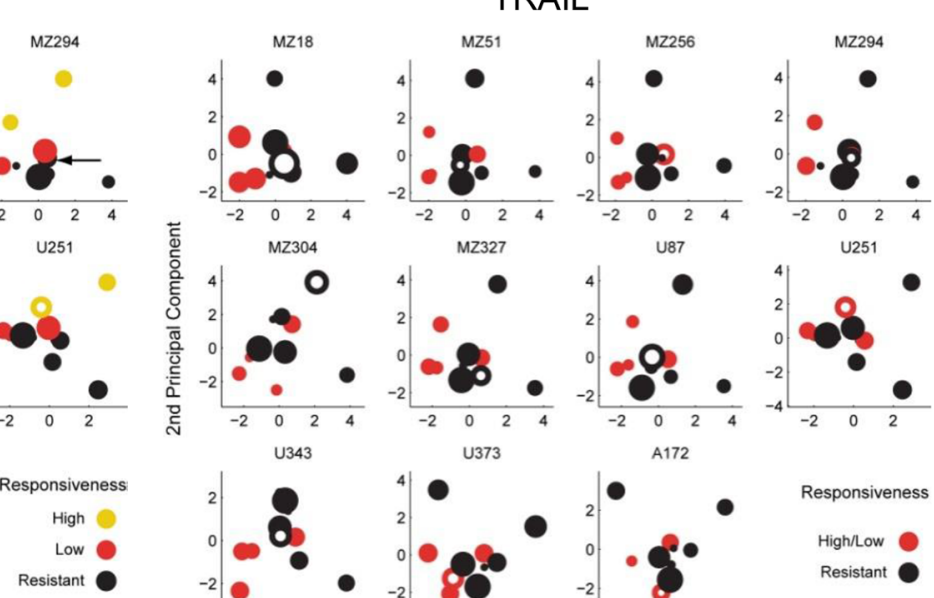

U251

U 343
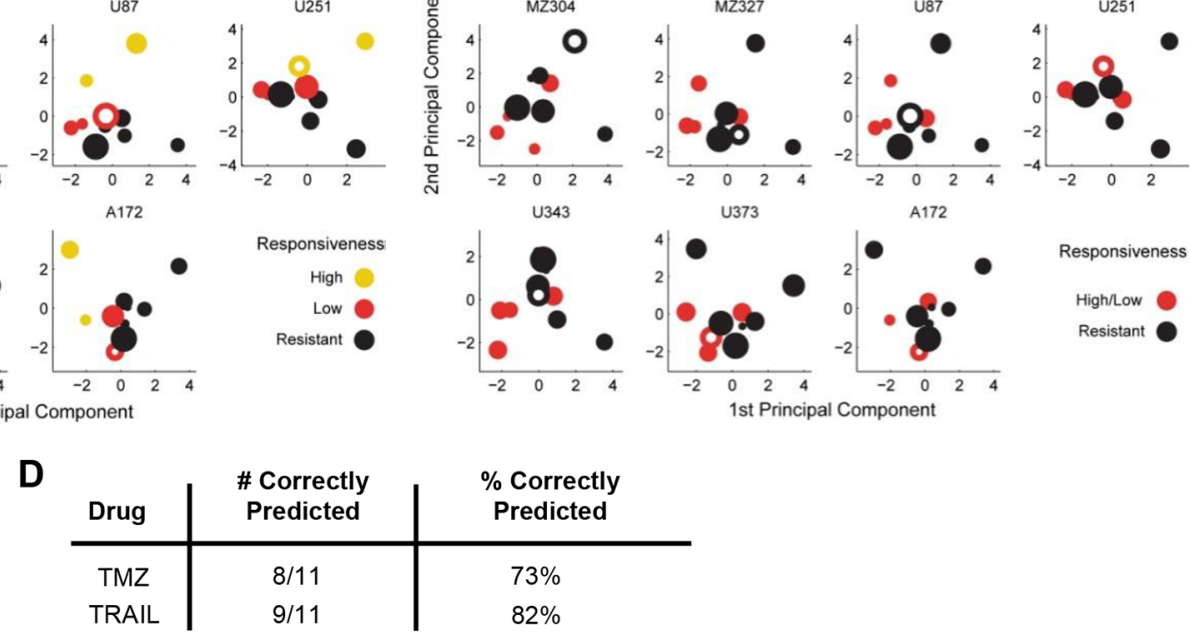

\section{E}

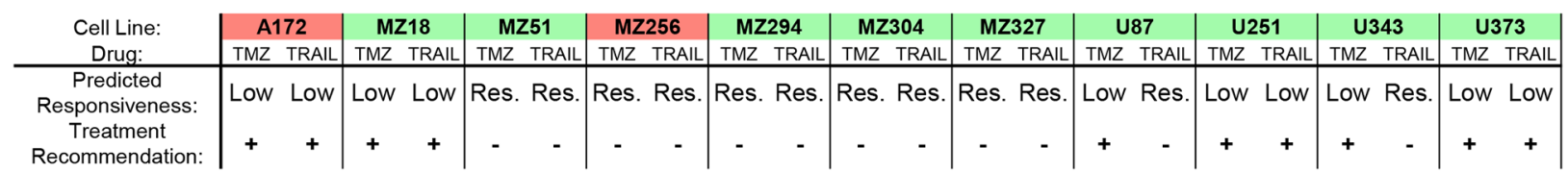

$\underset{\text { Responsivental }}{\text { Exs: }} \mid$ Low High|Res. Res.|Res. Res.|Res. Low $\mid$ Res. Res.|Res. Res.|Res. Res.|Low Res.|Res. Res.|High Res.|Low Low

Figure 3: Case-specific predictions of TMZ and TRAIL monotherapy responsiveness in GBM cell lines. A. Workflow for determining the predictive power of the model using leave-one-out cross-validation (LOOCV). All predictions were performed in 4D PC space. B,C. 2D projections of the PC spaces calculated from combinations of 10 cell lines are shown for TMZ and TRAIL treatments. Circle sizes decrease with distance from the viewer, thereby providing information on the third PC dimension. Open circles represent the test cell lines, which were placed into the PC spaces according to their functional group values. D. Performance scores for correctly predicting cell line responses to TMZ and TRAIL monotherapy. E. Case-specific predictions on TMZ and TRAIL responsiveness allow the in silico identification of optimal treatment options. Treatment recommendations were made according to the highest predicted responsiveness to TMZ or TRAIL and validated against experimental data. Green background indicates cases where optimal treatment options could be identified. Red background indicates cases where the better treatment option could be missed. 
into their respective response groups for TMZ treatment responsiveness (Figure 2G). For TRAIL responsiveness, only one highly responsive cell line was identified, which was pooled with the next highest responsiveness group for all subsequent analyses. LDA correctly classified 10/11 cell lines $(91 \%)$ for TRAIL responsiveness (Figure $2 \mathrm{G})$. Taken together, these findings indicate that protein data of key cell death regulators together with information on their interplay can be employed to separate GBM cell lines according to their TMZ and TRAIL responsiveness.

\section{Case specific predictions of TMZ and TRAIL monotherapy responsiveness allow the in silico identification of optimal treatments}

We next investigated whether the above findings can assist in predicting the responsiveness of individual cell lines to TMZ or TRAIL. We hypothesized that conducting the above analyses with a reduced number of cell lines may be sufficient to generate a PC space that can be segmented into spatial regions that reflect different levels of treatment responsiveness. We conducted a leave-one-out cross validation (LOOCV) in which we used the data from 10 cell lines and subsequently positioned the $11^{\text {th }}$ cell line into the LDA segmented PC space. If the placed cell line (test cell line) was positioned within the correct response region, the prediction was considered to be correct (Figure 3A). A visualization of the results limited to the first two PCs for TMZ and TRAIL response predictions is shown in Figure 3B, 3C. The prediction accuracies are summarized in Figure 3D; this demonstrates that TMZ and TRAIL responsiveness can be predicted with high accuracy ( $73 \%$ and $82 \%$ correct predictions, respectively).

In situations where multiple treatment options are available, treatment decision tools are required to assist in pre-selecting the optimal treatment option. An optimal treatment in our case (TMZ vs. TRAIL) was defined as the treatment that induces higher amounts of cell death for a given cell line. If both drugs cause similar amounts of cell death, either treatment suggestion was considered acceptable. Predictions were considered to have failed when the model recommended the treatment option with a lower effect on cell viability than the alternative treatment option. The performance of the model as a treatment decision tool is shown in Figure 3E. Treatment recommendations for the 11 cell lines were correct in $82 \%(9 / 11)$ of cases. These proof-of-concept results demonstrate that our modeling approach has the potential to identify best treatment options for individual cell lines with high accuracy.

\section{Capability to predict synergistic responses to TMZ and TRAIL}

It has previously been reported that combination therapy with TMZ/genotoxic agents and TRAIL may significantly enhance the responsiveness of highly treatment resistant cancer models, such as GBM cell lines [29-31]. We therefore next studied the responsiveness of the cell line panel to TMZ/TRAIL combination treatment. First, we investigated whether the response groups could be separated in the PC space and then we determined whether overall responsiveness as well as response synergies in these cell lines could be reliably predicted.

Overall, the responsiveness of the GBM cell line panel to TMZ/TRAIL treatment was improved when compared to the single agent treatments (Figure 4A, Figure 2D); this reduction in cell viability (Figure 4A) correlated with an increase in apoptotic cell death in TMZ and TRAIL-treated U251 cells, as evidenced by PARP cleavage and the prevention of such cleavage upon caspase inhibition (Supplementary Figure S1C), a significant increase in the number of Hoechst-labelled condensed nuclei (Supplementary Figure S1D), and caspase-3 substrate cleavage (Supplementary Figure S1E). No such cell death-related changes were evident in the treatment-resistant cell line, MZ294 (Supplementary Figure S1C, S1D, S1E). As with the single agent treatments, the response pattern to TMZ/TRAIL treatment was heterogeneous across the cell line panel, with both resistant and responsive cell lines identified (Figure 4A). Color coding the cell lines according to TMZ+TRAIL responsiveness again indicated that regions in the $\mathrm{PC}$ space appear to be associated with different levels of treatment responsiveness, and that these spatial regions can be separated by LDA (Supplementary Figure S2A, S1B). To test the predictive capacity of the model for TMZ+TRAIL combination treatment, we again conducted LOOCV (Supplementary Figure S2C). However, the responsiveness of only 6 out of the 11 cell lines was predicted correctly (55\%) (Supplementary Figure S2D).

Since the capacity of the model to predict cell line responsiveness to the dual treatment strategy of TMZ and TRAIL was limited, we next considered whether our modeling approach was better suited to study and predict response synergies. To this end, we first calculated the (CI) Value of each cell line using Webb's fractional product method [56], which provided us with a 'synergy score' for the combination treatment for each cell line (Supplementary Table S4); this was then used to place the cell lines in the PC space. Using this approach, we obtained regions in the $\mathrm{PC}$ space that allowed us to separate the cell lines by response synergies (Figure 4B). Furthermore, once we performed LOOCV using the CI Values, we found that we could successfully predict response synergies to TMZ and TRAIL combination therapy with 100\% accuracy (Figure 4C, 4D). Taken together, these results indicate that while prediction accuracies for the overall responsiveness to TMZ and TRAIL were limited, apoptosis protein expression patterns together with our modeling approach, were particularly powerful in predicting response synergies. 


\section{Accurate prediction of TRAIL sensitization by Bcl-2/Bcl-xL antagonist ABT-737}

The above analyses demonstrated that it is possible to predict from baseline protein expression profiles whether individual cell lines will respond to TMZ or TRAIL monotherapy. Since many of the GBM cell lines were resistant to TMZ or TRAIL or only responded poorly, we next investigated if our systems modeling approach could be used to predict whether poorly responsive cell lines could be sensitized to treatment by ABT-737. ABT737 specifically antagonizes Bcl-2 and Bcl-xL, the major

A

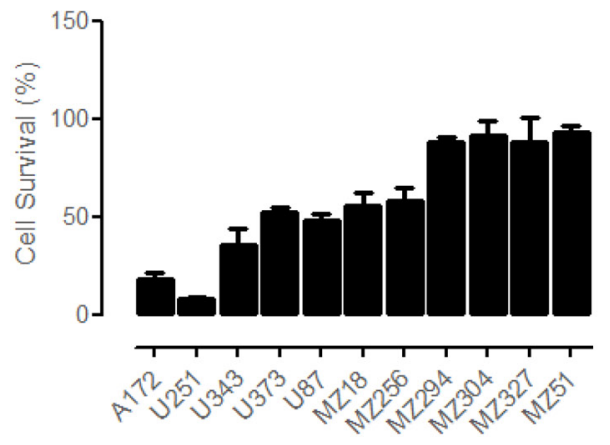

C
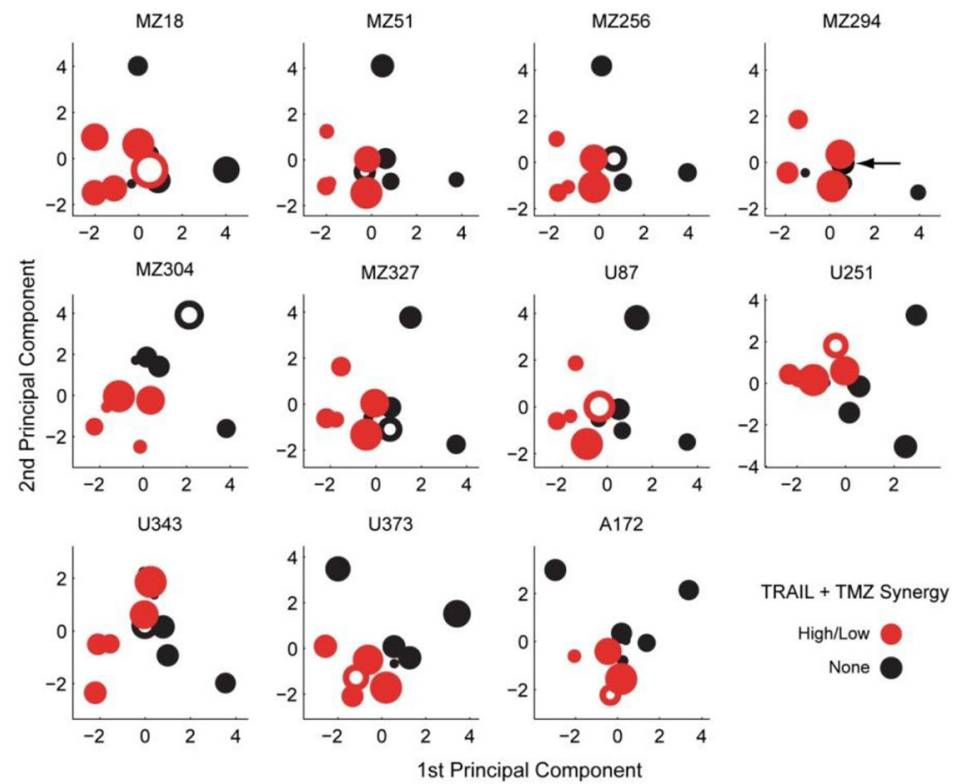

anti-apoptotic members of the Bcl-2 protein family, by binding to a hydrophobic groove of these proteins, thereby displacing bound activator $\mathrm{BH} 3$-only proteins and enabling the activation of pro-apoptotic Bax and Bak [57].

To generate predictions on which cell lines could be sensitized to TMZ or TRAIL by ABT-737, we first determined how the position of such cell lines in the PC space would change upon elimination of Bcl-2 and Bcl$\mathrm{xL}$. This repositioning was determined from the PCA results and the cell lines' protein profiles. The vector for the movement direction (Figure 5A) was determined by inverting and combining the coefficients of the FG for the

B

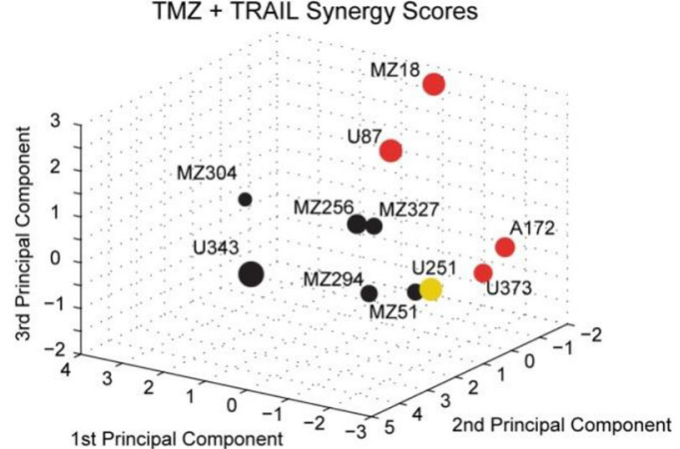

D

Figure 4: Predicting the synergy of TRAIL and TMZ combined therapy. A. Cell survival following TMZ and TRAIL combined therapy. Cells were treated with TMZ $(150 \mu \mathrm{M})$ and TRAIL $(100 \mathrm{ng} / \mathrm{ml})$ for $96 \mathrm{~h}$ and MTT assays were performed to assess cell viability. Data show cell survival relative to control values of $100 \%$ (mean \pm SEM from $n=3$ independent experiments). B. Cell lines in the $3 \mathrm{D}$ space were separated according to their Combination Index (CI) Value and color coded according to their response synergies to TMZ and TRAIL combined treatment. Visual inspection indicates the response regions are spatially separated. C. 2D projections of the PC spaces calculated from combinations of 10 cell lines are shown for TMZ/TRAIL combined treatments. Circle sizes decrease with distance from the viewer, thereby providing information on the third PC dimension. Open circles represent the test cell lines, which were placed into the PC spaces according to their CI Value. Note that the U251 cell line had to be grouped with the low responding cell lines in this analysis since it was alone in its response group. D. Performance scores for correctly predicting synergistic responses to TMZ/TRAIL combination therapy. 


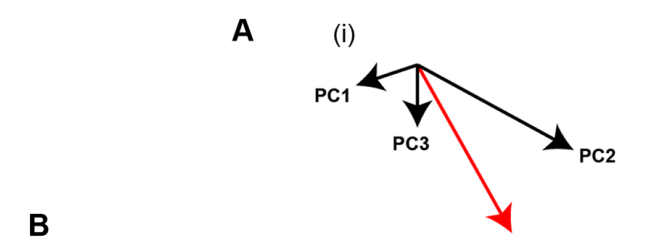

B
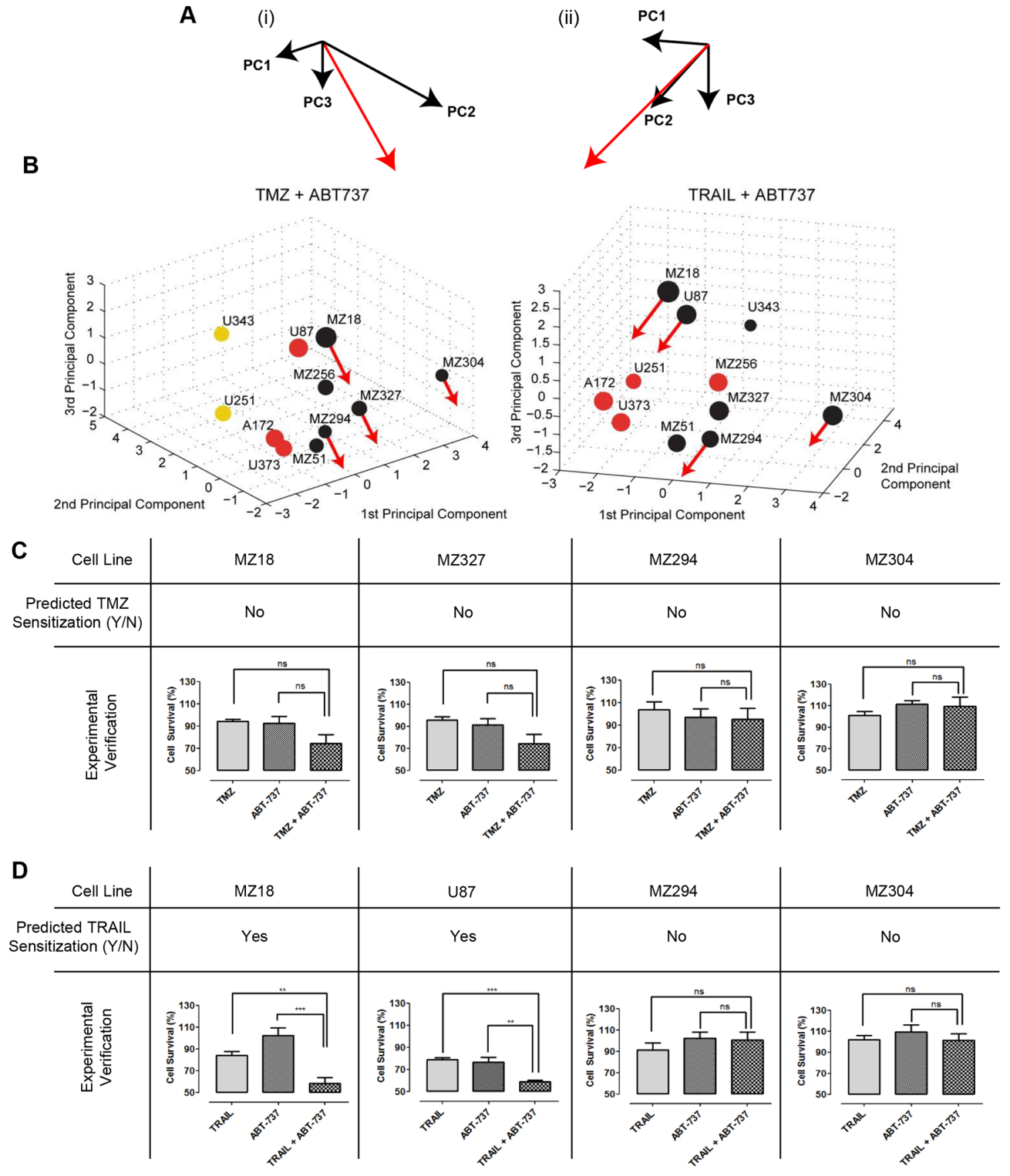

E
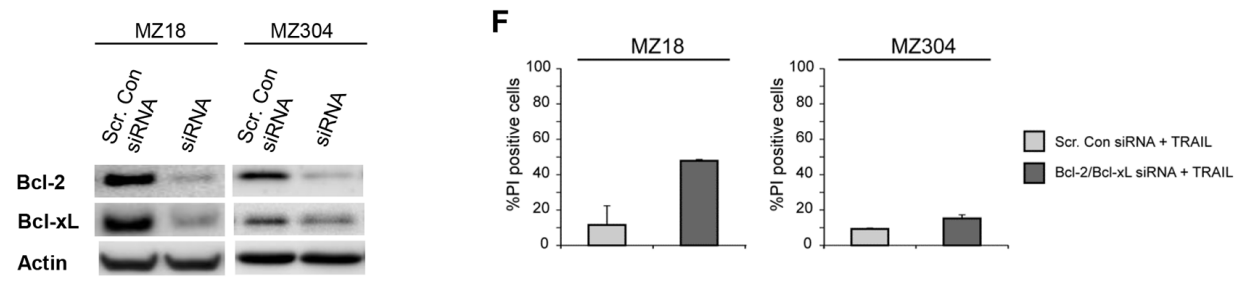

Figure 5: Prediction and experimental validation of GBM cell line sensitization to TRAIL or TMZ treatment by ABT-737. A. A movement vector (red) was calculated by combining the weightings for the (Bcl-2+Bcl-xL+Mcl-1) functional group in the first 3 PCs. (i) and (ii) provide different perspectives on the vectors, compatible with 3D PC spaces for TMZ or TRAIL responsiveness. B. 3D PC spaces for TMZ and TRAIL responsiveness with movement vectors applied to test cell lines. The length of the movement vectors was calculated from the respective $\mathrm{Bcl}-2$ and Bcl-xL content of the cell lines. Movement of treatment resistant cell lines towards regions populated by cell lines with higher treatment responsiveness predicts sensitization by the Bcl-2/Bcl-xL antagonist ABT-737. C, D, E. Experimental validation of predictions. Cell viability was measured for single and combination treatments. (C) Cells were treated with TMZ $(150 \mu \mathrm{M}) \pm$ ABT-737 $(1 \mu \mathrm{M})$ for $48 \mathrm{~h}$. (D) Cells were treated with TRAIL $(100 \mathrm{ng} / \mathrm{ml}) \pm$ ABT-737 $(1 \mu \mathrm{M})$ for $48 \mathrm{~h}$. Data show cell viability (mean \pm SEM from $\mathrm{n}=3$ independent experiments) in relation to untreated controls $(100 \%)$. One-way ANOVA with Bonferroni comparisons was performed for statistical analysis. ${ }^{* *} \mathrm{p}<0.01,{ }^{* * *} \mathrm{p}<0.001$. ns $=$ not significant. (E) Western blot analysis to confirm the successful knockdown of Bcl-2 and Bcl-xL. MZ18 and MZ304 cells were transfected with Bcl-2 and Bcl-xL esiRNA. F. siRNA depletion of Bcl-2 and Bcl-xL strongly sensitizes MZ18 but not MZ304 cells to TRAIL. Data show the number of $\mathrm{PI}^{+}$cells (mean \pm S.D. from triplicate samples) following treatment with TRAIL $(100 \mathrm{ng} / \mathrm{ml})$. Experiments were repeated with similar results. 
anti-apoptotic Bcl-2 proteins (Figure 2B); the distance moved depended on the amount of Bcl-2 and Bcl-xL that contributed to the $(\mathrm{Bcl}-2+\mathrm{Bcl}-\mathrm{xL}+\mathrm{Mcl}-1) \mathrm{FG}$ value in the respective cell lines (high amounts of Bcl-2 and Bcl-xL caused a more pronounced displacement). The resulting repositioning vectors were then applied to four representative cell lines that poorly responded to TMZ or TRAIL (MZ18, MZ294, MZ304, MZ327 cell lines and MZ18, U87, MZ304, MZ294 cell lines, respectively). For TMZ + ABT737 treatments, the movement vectors indicated that none of the cell lines would reposition closer to responding cell lines (Figure 5B), suggesting that ABT737 co-treatment would not sensitize these glioma cells to TMZ. For TRAIL + ABT737 treatments, the movement vectors indicated that MZ18 and U87, but not MZ294 and MZ304, cell lines would reposition closer to responding cell lines and thus be sensitized to TRAIL (Figure 5B).

These predictions were then validated experimentally. The selected cell lines were treated with either TMZ or TRAIL in the presence and absence of ABT-737 $(1 \mu \mathrm{M})$ for $48 \mathrm{~h}$. Cell viability measurements demonstrated that ABT-737 selectively sensitized MZ18 and U87 cells to TRAIL treatment, whereas ABT-737 did not sensitize any of the other cell lines to TMZ or TRAIL (Figure 5C, 5D). ABT-737 did not reduce cell viability on its own. These findings demonstrate that all predictions regarding ABT737-based sensitization could be validated (8/8), with our approach able to identify the subset of GBM cell lines that could be successfully sensitized to TRAIL by ABT737 co-treatment. To further validate these predictions, we used siRNA to knockdown Bcl-2 and Bcl-xL in MZ18 and MZ304 cells. As expected, our findings demonstrate that successful knockdown of Bcl-2 and Bcl-xL is sufficient to strongly sensitize MZ18 cells to TRAIL monotherapy. Our findings also demonstrate that, as predicted, Bcl-2 and Bcl-xL knockdown failed to notably raise the sensitivity of MZ304 cells to TRAIL monotherapy ( $<20 \%$ cell death). (Figure 5E, 5F). Overall, these findings demonstrate that the sensitizing effect of pharmacologically neutralizing anti-apoptotic Bcl-2 family members or by siRNA-based depletion can be accurately predicted by our approach.

\section{DISCUSSION}

Efficient induction of cell death is the aim of many anti-cancer therapies; thus, it follows that a cellular defect in cell death signaling pathways like apoptosis underlies one way in which these therapies can fail [32]. In apoptosis, death decisions are tightly controlled through multi-factorial and non-linear interplay of numerous regulatory proteins [58]; for this reason, indepth molecular analysis of any single protein, whether it be death-inducing or survival-promoting, is unlikely to yield an accurate prediction of drug responsiveness. Indeed, it is worth noting that no individual cell death regulating protein has so far been identified as a predictive or prognostic biomarker for GBM [59]. Instead, due to the complexity of apoptosis signaling, it seems rational that any potential insight gained from this cell death pathway should require analysis of all the key players involved. This, coupled with knowledge of how these players interact, has the potential to provide us with a much greater overview of a cell's capability to undergo apoptosis when confronted with a therapy that ultimately aims to achieve this mode of cell death. In this study, we applied this theory to both intrinsic (TMZ) and extrinsic (TRAIL) apoptosis-inducing therapies and successfully separated our panel of GBM cell lines according to their treatment response with $100 \%$ and $91 \%$ accuracy, respectively (Figure $2 \mathrm{G}$ ). This indicates that the complexity of the apoptosis signaling network as a whole needs to be taken into account for the implementation of successful predictive and prognostic strategies in GBM.

The functional groups defined in our study represent low numbers of proteins logically inter-related according to their biological interplay. This approach towards systems modeling is notably simplistic when compared to alternative modeling strategies, such as deterministic mathematical models that build on the use of differential equations [60]. The modeling strategy chosen here has the distinct advantage of being more versatile and easy to implement, amend and extend going forward. For example, to build on our proof-of-concept study with subsequent translational studies, we could include additional independent variables that pertain, for example, to the sub-type of GBM, thereby gaining knowledge of the driver mutations and their effect on cell death/survival signals. Age, Karnofsky performance score, extent of surgical resection and other clinicopathological factors influencing prognosis could also be included [61].

Importantly, once our cell lines were distributed in the PC space according to their protein expression profiles, we found little evidence of cell line overlap or clustering, indicative of the widespread heterogeneity found between the FGs of each cell line. This mirrors the extensive molecular heterogeneity found between GBM patients $[15,16]$ and backs the theory that a 'one-sizefits-all' approach to treating this disease, particularly with an apoptosis-targeted therapy, may not be valid [62]. Instead, in line with advocates of personalized medicine, it is conceivable that patients could be treated based on their unique set of molecular alterations in, or expression of, apoptosis regulators. For this, treatment decision tools such as ours will need to be developed and clinically validated in the future to assist in the pre-selection and stratification of patients for optimal therapies.

The prediction accuracy of our model was 73\% and $82 \%$ for TMZ and TRAIL treatments, respectively. The higher performance score for TRAIL was likely attributable to the fact that we included all critical TRAIL signaling components in our model. Furthermore, 
TRAIL-induced apoptosis is capable of proceeding independently of protein neo-synthesis, which suggests that baseline expression values for TRAIL signaling proteins is sufficient to predict the capacity of a cell to undergo TRAIL-induced apoptosis. The one obvious omission to the model, which may resolve any prediction error, is quantitative input for the TRAIL decoy receptors (DcR1 and DcR2). However, the level of decoy receptor expression in glioma cells is reportedly very low and therefore unlikely to account for TRAIL resistance [63]. Of course, we can't exclude the possibility that other cellular events could be influencing TRAIL susceptibility, such as survival signaling [64] and induction of cytoprotective autophagy $[65,66]$. For example, it is now known that in some cellular contexts TRAIL can engage $\mathrm{NF}_{\mathrm{k}} \mathrm{B}, \mathrm{PKB} /$ Akt and MAPKs signaling pathways, thereby contributing to cancer cell proliferation and migration as well as resistance to TRAIL-induced apoptosis [67]. Improving the predictive capacity for TMZ from baseline protein expression profiles may prove to be more difficult given that apoptosis occurs as a consequence of DNA damage and requires transcriptional and translational responses [4]. However, in this regard, future model extensions could take into account additional upstream events, such as DNA repair activity and p53 status as a main driver of transcriptional $\mathrm{BH} 3$-only protein induction $[68,69]$.

Cell line responsiveness to TMZ and TRAIL varied substantially, with individual cell lines frequently responding differently to TMZ and TRAIL monotherapy. This gave us the opportunity to assess whether our model could be exploited as a treatment decision tool. The prediction accuracy of our model was $82 \%$, with treatment recommendations correct 9 times out of 11 . However, it should be noted that few cell lines responded well to either treatment, highlighting once again the profound resistance of glioma cells to apoptotic stimuli and the need for more effective and rational combination therapies. In recent years, there has been an abundance of studies reporting on mechanisms to overcome apoptosis resistance in GBM for both established and novel therapies [24-32]. For the purpose of this study, we first focused on TMZ and TRAIL combination therapy, which in theory has the propensity to activate both the intrinsic and extrinsic apoptotic pathways, thereby enhancing both the likelihood of apoptosis induction as well as the strength of the apoptotic signal. In this case, our model only predicted the responsiveness of cell lines to TMZ+TRAIL with 55\% accuracy (Supplementary Figure S2D). This indicates that other factors need to be taken into account to more accurately predict TMZ+TRAIL responsiveness. Such factors may include additional molecular information, such as genetic alterations, resulting in the inactivation of apoptosis proteins or that may affect death/survival signals. Similarly, additional pathway cross-talk and/or the potentiation of signaling processes may need to be taken into account. For example, to address the synergistic manner in which TMZ and TRAIL come together to enhance apoptosis and in an attempt to determine whether knowledge of this synergy improves the predictive power of the model in co-treatment scenarios, we calculated the CI Value of each cell line [57]; this in turn allowed us to predict with $100 \%$ accuracy the response synergies of individual cells lines to TMZ+TRAIL (Figure 4C, 4D).

Strikingly, we were also able to predict cell line sensitivity to TMZ and TRAIL upon their co-treatment with ABT-737 with $100 \%$ accuracy, highlighting that the consequences of a targeted intervention are captured by our approach; this finding was further validated by siRNA depletion of Bcl-2 and Bcl-xL. In light of the recent FDA approval of the first Bcl-2 inhibitor, Venetoclax (ABT199), for patients with chronic lymphocytic leukemia with the $17 \mathrm{p}$ deletion, as well as the encouraging phase I-III clinical trials in development for Venetoclax as a monotherapy and/or combination therapy for various types of cancer [70], our capability to accurately predict the treatment outcome of a targeted intervention within the apoptosis signaling cascade is a particularly pertinent finding. Interestingly, ABT-737 failed to sensitize any GBM cell line to TMZ therapy, whilst in contrast MZ18 and U87 cells were sensitized to TRAIL. On the one hand, this may suggest that the expression levels of Bcl-2 and $\mathrm{Bcl}-\mathrm{xL}$ are irrelevant to $\mathrm{TMZ}$ resistance, at least within the expression ranges observed in our cell line panel, but on the other hand it also highlights the potential superiority of TRAIL-based therapies. TRAIL has long been perceived as a potential attractive chemotherapeutic agent, since it can kill cancer cells without conferring significant toxicity to normal cells [21], however, to date, no TRAILbased therapy has demonstrated both potency and lack of systemic toxicity in any clinical trial $[17,22,23]$. Besides the limitations of previous TRAIL-based therapeutics, that are now being addressed in the design of superior $2^{\text {nd }}$ generation receptor ligands [71, 72], it is our conjecture that the lack of patient pre-selection in these trials may have contributed to their disappointing outcomes.

With the era of personalized medicine looming, our approach, if validated translationally in subsequent studies, could help to stratify patients for TRAIL monoor combination therapies. Such translational studies would initially require use of large-scale quantitative protein data from fresh or archived GBM tissue as well as the identification of high quality antibodies for the use of high through-put screening methods, like reverse phase protein or tissue micro arrays. For a clinical setting, our model could be refined to focus on cancer stem cell populations, believed to be the tumor initiating cells that drive the growth, progression and invasion of GBMs as well as their post-treatment recurrence [73-75]. In this regard, quantitative protein analysis of this highly tumorigenic sub-population of cells could provide us with crucial insight into whether tumor cells not surgically removed will respond to treatment. 
In conclusion, we have described the first preclinical proof-of-principle study that merges quantitative protein-based analysis of apoptosis signaling networks with data- and knowledge-driven mathematical systems modeling to predict treatment responsiveness of GBM cell lines to various apoptosis-inducing stimuli. Furthermore, we have shown that a systems biology-based approach could assist in personalizing treatment decisions in GBM to optimize cell death induction.

\section{MATERIALS AND METHODS}

\section{Materials}

TMZ was purchased from Sigma-Aldrich Ireland Ltd (Dublin, Ireland). Human recombinant TRAIL was purchased from Enzo Life Science (UK) Ltd (Exeter, United Kingdom). ABT-737 was purchased from Biorbyt (Riverside, United Kingdom), and Bcl-2 and Bcl-xL esiRNAs were purchased from Sigma-Aldrich Ireland Ltd (Dublin, Ireland).

\section{GBM cell lines}

GBM cell lines A172, U87, U251, U343 and U373 are commercially available from the ATCC. GBM cell lines MZ18, MZ51, MZ294, MZ304, MZ327, and MZ256 were kindly donated by Professor Donat Kögel of Johann Wolfgang Goethe University Hospital, Frankfurt, Germany and have previously been characterized [76]. The cells were grown in Dulbecco's modified Eagle's medium (DMEM) with 10\% heat-inactivated fetal calf serum, $100 \mathrm{U} / \mathrm{ml}$ penicillin and $100 \mathrm{mg} / \mathrm{ml}$ streptomycin and were maintained in a humidified incubator at $37^{\circ} \mathrm{C}$ and $5 \% \mathrm{CO}_{2}$

\section{Western blot analysis}

In order to determine the basal expression level of apoptotic proteins, GBM cell lines were homogenized in lysis buffer containing $0.5 \mathrm{mmol} / 1$ Tris- $\mathrm{HCl}$ (pH6.8), $2 \% \operatorname{SDS}(\mathrm{w} / \mathrm{v}), 10 \%$ glycerine $(\mathrm{w} / \mathrm{v})$, and protease and phosphatase inhibitor cocktails (Sigma-Aldrich). After determining the protein concentration of samples using a BCA protein assay (Pierce, Rockford, IL, USA), $20 \mu \mathrm{g}$ samples were boiled in gel-loading buffer and separated on $10-15 \%$ SDS-PAGE gels. Proteins were transferred to nitrocellulose membranes using the iBlot gel transfer device (Life Technologies, Invitrogen, Paisley, Scotland). The membranes were blocked in 5\% non-fat milk in TBST for $1 \mathrm{~h}$ at room temperature prior to being incubated with primary antibodies overnight at $4^{\circ} \mathrm{C}$. The following primary antibodies were used: rabbit polyclonal Apaf-1 (Cat\# 16941, Millipore); rabbit polyclonal Bak (Cat\# sc832, Santa Cruz); rabbit polyclonal Bax (Cat\# 06-499, Upstate Biotechnology); mouse monoclonal Bcl-2
(Cat\# sc-509, Santa Cruz); mouse monoclonal Bcl-xL (Cat\# sc-8392); rabbit polyclonal Bid (Cat\# 2002, Cell Signaling); rabbit monoclonal Bim (Cat\# 2933, Cell Signaling); rabbit polyclonal caspase-3 (Cat\# 9662, Cell Signaling); mouse monoclonal caspase-8 (Cat\# ALX-804-242, Enzo Life Sciences); rabbit polyclonal caspase-9 (Cat\# 9502, Cell Signaling); mouse monoclonal cFLIP (Cat\# ALX-804-428, Enzo Life Sciences); mouse monoclonal FADD (Cat\# 610399, BD Biosciences); mouse monoclonal Mcl-1 (Cat\# 559027, BD Biosciences); mouse monoclonal Noxa (Cat\# 13654, Abcam); rabbit polyclonal PUMA (Cat\# 3041, ProSci Incorporated); mouse monoclonal SMAC/DIABLO (Cat\# 2954, Cell Signaling); and mouse monoclonal XIAP (Cat\# 610763, BD Biosciences); and mouse monoclonal $\beta$-actin (Cat\# A5441, Sigma-Aldrich). Membranes were then washed three times with TBST for $5 \mathrm{~min}$ prior to being incubated with peroxidase-conjugated secondary antibodies (anti-mouse or anti-rabbit; Millipore) for $1 \mathrm{~h}$ at room temperature. Protein bands were visualized using the Immobilin western chemiluminescence HRP substrate (Millipore) and images were captured using a LAS-4000 imager equipped with a cooled 12 bit digital CCD camera (Fujifilm UK Ltd, Bedfordshire, UK). To guarantee accurate quantifications, special care was taken not to over-expose the protein bands. Densitometry was carried out on 12-bit raw images using Image J 1.4.10 software (National Institute of Heath, Bethesda, MD, USA; http://rsb.info.nih.gov/ij). For each protein, the integrated density of the signal was measured, corrected for background signals and normalized to a $\beta$-actin loading control. Standard curves from HeLa cell extracts (5-20 mg) were run concurrently with the GBM cell line extracts to ensure linearity of the signal detection range. The absolute concentration of most proteins of interest was previously determined in HeLa cells [77-79], so that HeLa cell signals could be used to calculate protein concentrations in GBM cell lines. Quantifications were carried out on at least 3 independent membranes. Cleavage of caspase- 8 and caspase- 3 was also assessed in A172 and MZ304 cells following TRAIL treatment $(100 \mathrm{ng} / \mathrm{ml})$ in the presence of the caspase inhibitor, zVAD-fmk (150 $\mu \mathrm{M}$; 30 min pre-treatment) for 24 and $96 \mathrm{~h}$, respectively. Cleavage of PARP was assessed in MZ294 and U251 cells following the combined treatment of TRAIL $(100 \mathrm{ng} / \mathrm{ml})$ $+\mathrm{TMZ}(150 \mu \mathrm{M})$ in the presence or absence of zVAD-fmk (150 $\mu \mathrm{M}$; $30 \mathrm{~min}$ pre-treatment) for $96 \mathrm{~h}$.

\section{Flow cytometry}

The basal surface expression of DR4 and DR5 were assessed using a BD LSR II flow cytometer (BD Biosciences). Briefly, 1 x $10^{5}$ cells were seeded into 6 well plates and allowed to adhere overnight. Cells were then harvested with trypsin-EDTA and pelleted by centrifugation at $1200 \mathrm{rpm}$ for $5 \mathrm{~min}$ at $4^{\circ} \mathrm{C}$. Following incubation with a blocking buffer $(0.5 \% \mathrm{BSA})$ on ice for 
$20 \mathrm{~min}$, cells were incubated with a mouse monoclonal antibody for DR4 (Cat\# ab13890, Abcam; 1:100 dilution) or DR5 (Cat\# ALX-804-914-0100, Enzo life sciences; 1:100 dilution) for $30 \mathrm{~min}$, pelleted and washed $\mathrm{x} 3$ with PBS, and then incubated with a secondary anti-mouse FITC-conjugated antibody (Life Technologies, Invitrogen, Paisley, Scotland; 1:200 dilution) for $30 \mathrm{~min}$ in the dark. Controls were stained with secondary antibody only. FITC was excited at $488 \mathrm{~nm}$ and fluorescence emission was collected in the FL1 channel through a $520 \mathrm{~nm}$ bandpass filter. A total of $1 \times 10^{4}$ gated cells were acquired for each cell line. The relative expression of DR4 and DR5 was determined by comparison of specific staining intensities compared to individual cell line negative controls. For cell death measurements, flow cytometry was used to assess the number of Annexin $\mathrm{V}^{+}$cells following treatment with TRAIL (100 ng/ml) or TRAIL+TMZ (150 $\mu \mathrm{M})$ in the presence or absence of zVAD-fmk $(150 \mu \mathrm{M}$; $30 \mathrm{~min}$ pre-treatment) for $96 \mathrm{~h}$ as well as the number of $\mathrm{PI}^{+}$cells following transfection with $\mathrm{Bcl}-2 / \mathrm{Bcl}-\mathrm{xL}$ siRNA and treatment with TRAIL $(100 \mathrm{ng} / \mathrm{ml})$ for $48 \mathrm{~h}$. Briefly, cells were seeded into 6-well plates and allowed to adhere overnight. Following appropriate treatment conditions, cells were pelleted and incubated in $100 \mu \mathrm{l}$ of binding buffer (10 nM HEPES, $135 \mathrm{nM} \mathrm{NaCl}, 5 \mathrm{mM}$ $\left.\mathrm{CaCl}_{2}\right)$ containing AnnexinV- FITC conjugate $(5 \mu \mathrm{l} / \mathrm{ml})$ (BioVision, Moutain View, CA, USA) for $10 \mathrm{~min}$ on ice in the dark or in DMEM containing PI $(1.33 \mu \mathrm{g} / \mathrm{ml})$ for 15 $\min$ at $37^{\circ} \mathrm{C}$. FITC was excited at $488 \mathrm{~nm}$ and fluorescence emission was collected in the FL1 channel through a $520 \mathrm{~nm}$ band-pass filter. PI was excited at $561 \mathrm{~nm}$ and fluorescence emission was collected through a 605/40 nm band-pass filter and a $570 \mathrm{~nm}$ long pass filter. A total of $1 \times 10^{4}$ gated cells were acquired for each cell line.

\section{Cell transfection}

To downregulate $\mathrm{Bcl}-2$ and $\mathrm{Bcl}-\mathrm{xL}$ protein expression, we used endoribonuclease-prepared small interfering RNAs (esiRNAs), which are comprised of a heterogeneous mixture of siRNAs that all target the same mRNA sequence (Cat\# EHU135281 and EHU087041, Sigma-Aldrich). Briefly, MZ18 and MZ304 cells were transfected with $1 \mu \mathrm{g}$ of Bcl-2 esiRNA and $1 \mu \mathrm{g}$ of Bcl$\mathrm{xL}$ esiRNA for $4 \mathrm{~h}$ using LipofectamineTM 2000 in antibiotic-free Opti-MEM medium (Life Technologies, Invitrogen, Paisley, Scotland). Following this incubation period, the transfection mixture was replaced with fresh DMEM and the cells were allowed to recover for $48 \mathrm{~h}$, after which they were used for experiments.

\section{Cell viability measurements}

GBM cell lines were seeded into 96-well plates (2000 cells/well) and allowed to adhere overnight. To validate cell line responsiveness to TMZ and TRAIL monotherapy, cells were treated at clinically-informed "maximum effect" (Emax) conditions and accordingly were treated with TMZ $(150 \mu \mathrm{M})$ or TRAIL (100 ng/ $\mathrm{ml}$ ) for $96 \mathrm{~h}$. To confirm cell lines responsiveness to TRAIL and TMZ combined therapy, cells were treated with TRAIL $(100 \mathrm{ng} / \mathrm{ml})$ and TMZ $(150 \mu \mathrm{M})$ for $96 \mathrm{~h}$. To substantiate the sensitization of cell lines to TRAIL or TMZ with ABT-737, cells were either treated with TRAIL $(100 \mathrm{ng} / \mathrm{ml})$ in the presence or absence of ABT-737 $(1 \mu \mathrm{M})$ for $48 \mathrm{~h}$ or with TMZ $(150 \mu \mathrm{M})$ in the presence or absence of ABT-737 $(1 \mu \mathrm{M})$ for $48 \mathrm{~h}$. Following treatment, cells were incubated with thiazolyl blue tetrazolium bromide (MTT; 5mg/ml; Sigma-Aldrich Ireland Ltd) for $4 \mathrm{~h}$ at $37^{\circ} \mathrm{C}$, after which the medium was aspirated and replaced with DMSO $(200 \mu \mathrm{l})$. The absorbance of each sample was measured at $560 \mathrm{~nm}$ using a microplate reader (GENios, Tecan, Mannedorf, Switzerland). MTT is a yellow tetrazole that is converted to dark blue/purple formazan by mitochondrial dehydrogenase of living cells. Thus, the absorbance value for each sample was considered proportional to the number of viable cells.

\section{Hoechst staining}

MZ294 and U251 cells were stained with Hoechst $33258(1 \mu \mathrm{g} / \mathrm{ml})$ for $20 \mathrm{~min}$. Changes in nuclear morphology were detected by epifluorescence microscopy (Nikon Eclipse TE300). Normal bright field images were taken to examine morphological changes, such as cell shrinkage and membrane blebbing.

\section{Caspase- 3 substrate cleavage}

DEVDase (Caspase-3-like) activity was determined fluorometrically using carbobenzoxy-Asp-Glu-ValAsp-7-amino-4-methyl-coumarin (DEVD-AMC) as substrate. Cleavage of DEVD-AMC to liberate free AMC was monitored by measuring fluorescence after 1 and $2 \mathrm{~h}$ intervals. Protein content was determined using Pierce Coomassie Plus Protein assay reagent (Perbio, Northumberland, UK). Caspase activity is expressed as a change in fluorescent units per hour and per microgram protein.

\section{Statistical analysis}

Student's t-test or one-way ANOVA with post hoc Bonferroni test were performed to identify statistically significant differences between treatment groups. $P$-values are indicated in the figure panels and legends.

\section{Data processing and analysis for knowledge- and data-driven systems modeling}

All data processing and analysis was performed using a programming code developed for MATLAB 2007b (The Mathworks, UK), equipped with the statistics toolbox; a detailed description of the procedures has 
previously been published [37]. In brief, following the integration of protein expression data into functional groups, a PCA was performed [38, 39]. PCs with eigenvalues above 1 were retained, according to the Kaiser criterion [80, 81]. Scatter plots were generated from the first three PCs to visualize the data. LDA [82] was employed to determine the accuracy of response class separations in the PC space. LOOCV was applied to iteratively test the prediction capacity of the model for the entire cell line ensemble. LDA was applied after each iteration to determine if the test cell lines positioned in the PC space region that corresponded to its drug responsiveness. To predict sensitization effects of ABT737 in co-treatment scenarios, the protein values for the target proteins, $\mathrm{Bcl}-2$ and $\mathrm{Bcl}-\mathrm{xL}$, were set to zero and the re-positioning of cell lines of choice in the PC space was investigated. Re-positioning towards PC space regions of higher responsiveness were interpreted as a prediction for successful sensitization. A detailed description for this procedure is available in [37].

\section{Abbreviations}

temozolomide, TMZ; glioblastoma, GBM; tumor necrosis factor-related apoptosis-inducing ligand, TRAIL; death receptor 4/5, DR4/5; inhibitor of apoptosis protein, IAP; functional groups, FG; fas-associated death domain, FADD; death-inducing signaling complex, DISC; death effector domain, DED; mitochondrial outer membrane permeabilisation, MOMP; second mitochondria-derived activator of caspases, SMAC; apoptotic protease activating factor 1, Apaf-1; principle component analysis, PCA; linear discriminant analysis, LDA; leave-one-out cross validation, LOOCV; epidermal growth factor receptor, EGFR; platelet-derived growth factor receptor, PDGFR; small interfering RNA, siRNA.

\section{ACKNOWLEDGMENTS AND FUNDING}

The authors kindly acknowledge support for their work by grants from the Irish Health Research Board (HRA_POR/2012/88 and HRA_POR/2013/245), the RCSI Research Committee (GR 08-0155) and the European Union (FP7 IAPP SYS-MEL; FP7 APO-DECIDE; Horizon 2020 MSC ETN MEL-PLEX, Horizon 2020 MSC ETN TRAIN-ERS).

\section{CONFLICTS OF INTEREST}

The authors declare no conflicts of interest.

\section{REFERENCES}

1. Stupp R, Mason WP, van den Bent MJ, Weller M, Fisher B, Taphoorn MJ, Belanger K, Brandes AA, Marosi C, Bogdahn U, Curschmann J, Janzer RC, Ludwin SK, et al.
Radiotherapy plus concomitant and adjuvant temozolomide for glioblastoma. The New England journal of medicine. 2005; 352:987-996.

2. Mrugala MM and Chamberlain MC. Mechanisms of disease: temozolomide and glioblastoma-look to the future. Nature clinical practice Oncology. 2008; 5:476-486.

3. Mirimanoff RO, Gorlia T, Mason W, Van den Bent MJ, Kortmann RD, Fisher B, Reni M, Brandes AA, Curschmann J, Villa S, Cairncross G, Allgeier A, Lacombe D, et al. Radiotherapy and temozolomide for newly diagnosed glioblastoma: recursive partitioning analysis of the EORTC 26981/22981-NCIC CE3 phase III randomized trial. Journal of clinical oncology. 2006; 24:2563-2569.

4. Quiros S, Roos WP and Kaina B. Processing of O6-methylguanine into DNA double-strand breaks requires two rounds of replication whereas apoptosis is also induced in subsequent cell cycles. Cell Cycle. 2010; 9:168-178.

5. Hegi ME, Diserens AC, Gorlia T, Hamou MF, de Tribolet N, Weller M, Kros JM, Hainfellner JA, Mason W, Mariani L, Bromberg JE, Hau P, Mirimanoff RO, et al. MGMT gene silencing and benefit from temozolomide in glioblastoma. The New England journal of medicine. 2005; 352:997-1003.

6. Gilbert MR, Wang M, Aldape KD, Stupp R, Hegi ME, Jaeckle KA, Armstrong TS, Wefel JS, Won M, Blumenthal DT, Mahajan A, Schultz CJ, Erridge S, et al. Dose-dense temozolomide for newly diagnosed glioblastoma: a randomized phase III clinical trial. Journal of clinical oncology. 2013; 31:4085-4091.

7. Felsberg J, Thon N, Eigenbrod S, Hentschel B, Sabel MC, Westphal M, Schackert G, Kreth FW, Pietsch T, Loffler M, Weller M, Reifenberger G, Tonn JC, et al. Promoter methylation and expression of MGMT and the DNA mismatch repair genes MLH1, MSH2, MSH6 and PMS2 in paired primary and recurrent glioblastomas. International journal of cancer. 2011; 129:659-670.

8. Malmstrom A, Gronberg BH, Marosi C, Stupp R, Frappaz D, Schultz H, Abacioglu U, Tavelin B, Lhermitte B, Hegi ME, Rosell J, Henriksson R and Nordic Clinical Brain Tumour Study G. Temozolomide versus standard 6-week radiotherapy versus hypofractionated radiotherapy in patients older than 60 years with glioblastoma: the Nordic randomised, phase 3 trial. The Lancet Oncology. 2012; 13:916-926.

9. Wick W, Platten M, Meisner C, Felsberg J, Tabatabai G, Simon M, Nikkhah G, Papsdorf K, Steinbach JP, Sabel M, Combs SE, Vesper J, Braun C, et al. Temozolomide chemotherapy alone versus radiotherapy alone for malignant astrocytoma in the elderly: the NOA-08 randomised, phase 3 trial. The Lancet Oncology. 2012; 13:707-715.

10. Grossman SA, Ye X, Chamberlain M, Mikkelsen T, Batchelor T, Desideri S, Piantadosi S, Fisher J and Fine HA. Talampanel with standard radiation and temozolomide in patients with newly diagnosed glioblastoma: a multicenter phase II trial. Journal of clinical oncology. 2009; 27:4155-4161. 
11. Peereboom DM, Shepard DR, Ahluwalia MS, Brewer CJ, Agarwal N, Stevens GH, Suh JH, Toms SA, Vogelbaum MA, Weil RJ, Elson P and Barnett GH. Phase II trial of erlotinib with temozolomide and radiation in patients with newly diagnosed glioblastoma multiforme. Journal of neuro-oncology. 2010; 98:93-99.

12. Weiler M, Hartmann C, Wiewrodt D, Herrlinger U, Gorlia T, Bahr O, Meyermann R, Bamberg M, Tatagiba M, von Deimling A, Weller M and Wick W. Chemoradiotherapy of newly diagnosed glioblastoma with intensified temozolomide. International journal of radiation oncology, biology, physics. 2010; 77:670-676.

13. Lai A, Tran A, Nghiemphu PL, Pope WB, Solis OE, Selch M, Filka E, Yong WH, Mischel PS, Liau LM, Phuphanich S, Black K, Peak S, et al. Phase II study of bevacizumab plus temozolomide during and after radiation therapy for patients with newly diagnosed glioblastoma multiforme. Journal of clinical oncology. 2011; 29:142-148.

14. Wick W, Weller M, van den Bent M, Sanson M, Weiler M, von Deimling A, Plass C, Hegi M, Platten M and Reifenberger G. MGMT testing--the challenges for biomarker-based glioma treatment. Nature reviews Neurology. 2014; 10:372-385.

15. Inda MM, Bonavia $\mathrm{R}$ and Seoane J. Glioblastoma multiforme: a look inside its heterogeneous nature. Cancers. 2014; 6:226-239.

16. Eder $\mathrm{K}$ and Kalman B. Molecular heterogeneity of glioblastoma and its clinical relevance. POR. 2014; 20:777-787.

17. Lemke J, von Karstedt S, Zinngrebe J and Walczak H. Getting TRAIL back on track for cancer therapy. Cell death and differentiation. 2014; 21:1350-1364.

18. Stuckey DW and Shah K. TRAIL on trial: preclinical advances in cancer therapy. Trends in molecular medicine. 2013; 19:685-694.

19. Nagpal J, Jamoona A, Gulati ND, Mohan A, Braun A, Murali $\mathrm{R}$ and Jhanwar-Uniyal M. Revisiting the role of p53 in primary and secondary glioblastomas. Anticancer research. 2006; 26:4633-4639.

20. Chiang MF, Chou PY, Wang WJ, Sze CI and Chang NS. Tumor Suppressor WWOX and p53 Alterations and Drug Resistance in Glioblastomas. Frontiers in oncology. 2013; 3:43.

21. Walczak H, Miller RE, Ariail K, Gliniak B, Griffith TS, Kubin M, Chin W, Jones J, Woodward A, Le T, Smith C, Smolak P, Goodwin RG, et al. Tumoricidal activity of tumor necrosis factor-related apoptosis-inducing ligand in vivo. Nature medicine. 1999; 5:157-163.

22. de Miguel D, Lemke J, Anel A, Walczak H and MartinezLostao L. Onto better TRAILs for cancer treatment. Cell death and differentiation. 2016; 23:733-747.

23. Dimberg LY, Anderson CK, Camidge R, Behbakht K, Thorburn A and Ford HL. On the TRAIL to successful cancer therapy? Predicting and counteracting resistance against TRAIL-based therapeutics. Oncogene. 2013; 32:1341-1350.
24. Murphy AC, Weyhenmeyer B, Noonan J, Kilbride SM, Schimansky S, Loh KP, Kogel D, Letai AG, Prehn JH and Murphy BM. Modulation of Mcl-1 sensitizes glioblastoma to TRAIL-induced apoptosis. Apoptosis. 2014; 19:629-642.

25. van Roosmalen IA, Reis CR, Setroikromo R, Yuvaraj S, Joseph JV, Tepper PG, Kruyt FA and Quax WJ. The ER stress inducer DMC enhances TRAIL-induced apoptosis in glioblastoma. SpringerPlus. 2014; 3:495.

26. Bangert A, Cristofanon S, Eckhardt I, Abhari BA, Kolodziej S, Hacker S, Vellanki SH, Lausen J, Debatin KM and Fulda S. Histone deacetylase inhibitors sensitize glioblastoma cells to TRAIL-induced apoptosis by c-myc-mediated downregulation of cFLIP. Oncogene. 2012; 31:4677-4688.

27. Cristofanon S and Fulda S. ABT-737 promotes tBid mitochondrial accumulation to enhance TRAIL-induced apoptosis in glioblastoma cells. Cell death \& disease. 2012; 3:e432.

28. Fulda S, Wick W, Weller M and Debatin KM. Smac agonists sensitize for Apo2L/TRAIL- or anticancer drug-induced apoptosis and induce regression of malignant glioma in vivo. Nature medicine. 2002; 8:808-815.

29. Kim SM, Woo JS, Jeong CH, Ryu CH, Jang JD and Jeun SS. Potential application of temozolomide in mesenchymal stem cell-based TRAIL gene therapy against malignant glioma. Stem cells translational medicine. 2014; 3:172-182.

30. Hingtgen S, Ren X, Terwilliger E, Classon M, Weissleder $\mathrm{R}$ and Shah $\mathrm{K}$. Targeting multiple pathways in gliomas with stem cell and viral delivered S-TRAIL and Temozolomide. Molecular cancer therapeutics. 2008; 7:3575-3585.

31. Saito R, Bringas JR, Panner A, Tamas M, Pieper RO, Berger MS and Bankiewicz KS. Convection-enhanced delivery of tumor necrosis factor-related apoptosis-inducing ligand with systemic administration of temozolomide prolongs survival in an intracranial glioblastoma xenograft model. Cancer research. 2004; 64:6858-6862.

32. Krakstad $\mathrm{C}$ and Chekenya M. Survival signalling and apoptosis resistance in glioblastomas: opportunities for targeted therapeutics. Molecular cancer. 2010; 9:135.

33. Billard C. BH3 mimetics: status of the field and new developments. Molecular cancer therapeutics. 2013; 12:1691-1700.

34. Bai L, Smith DC and Wang S. Small-molecule SMAC mimetics as new cancer therapeutics. Pharmacology \& therapeutics. 2014; 144:82-95.

35. Tagscherer KE, Fassl A, Campos B, Farhadi M, Kraemer A, Bock BC, Macher-Goeppinger S, Radlwimmer B, Wiestler OD, Herold-Mende C and Roth W. Apoptosis-based treatment of glioblastomas with ABT-737, a novel small molecule inhibitor of $\mathrm{Bcl}-2$ family proteins. Oncogene. 2008; 27:6646-6656.

36. Yang MC, Loh JK, Li YY, Huang WS, Chou CH, Cheng JT, Wang YT, Lieu AS, Howng SL, Hong YR and Chou AK. Bcl2L12 with a BH3-like domain in regulating apoptosis and TMZ-induced autophagy: a prospective combination 
of ABT-737 and TMZ for treating glioma. International journal of oncology. 2015; 46:1304-1316.

37. Passante E, Wurstle ML, Hellwig CT, Leverkus M and Rehm M. Systems analysis of apoptosis protein expression allows the case-specific prediction of cell death responsiveness of melanoma cells. Cell death and differentiation. 2013; 20:1521-1531.

38. H H. Analysis of a complex of statistical variables into principal components. J Educ Psych. 1933; 24:417.

39. Pearson K. On lines and planes of closest fit to systems of points in space. Philosophical Magazine. 1901; 2:599-572.

40. Kischkel FC, Hellbardt S, Behrmann I, Germer M, Pawlita M, Krammer PH and Peter ME. Cytotoxicity-dependent APO-1 (Fas/CD95)-associated proteins form a deathinducing signaling complex (DISC) with the receptor. The EMBO journal. 1995; 14:5579-5588.

41. Parrish AB, Freel CD and Kornbluth S. Cellular mechanisms controlling caspase activation and function. Cold Spring Harbor perspectives in biology. 2013; 5.

42. Luo X, Budihardjo I, Zou H, Slaughter C and Wang X. Bid, a Bcl2 interacting protein, mediates cytochrome c release from mitochondria in response to activation of cell surface death receptors. Cell. 1998; 94:481-490.

43. Shamas-Din A, Brahmbhatt H, Leber B and Andrews DW. $\mathrm{BH} 3$-only proteins: Orchestrators of apoptosis. Biochimica et biophysica acta. 2011; 1813:508-520.

44. Lomonosova $\mathrm{E}$ and Chinnadurai G. BH3-only proteins in apoptosis and beyond: an overview. Oncogene. 2008; 27 Suppl 1:S2-19.

45. Strasser A, Cory S and Adams JM. Deciphering the rules of programmed cell death to improve therapy of cancer and other diseases. The EMBO journal. 2011; 30:3667-3683.

46. Rodriguez-Nieto S and Zhivotovsky B. Role of alterations in the apoptotic machinery in sensitivity of cancer cells to treatment. Current pharmaceutical design. 2006; 12:4411-4425.

47. Lin CJ, Lee CC, Shih YL, Lin CH, Wang SH, Chen $\mathrm{TH}$ and Shih CM. Inhibition of mitochondria- and endoplasmic reticulum stress-mediated autophagy augments temozolomide-induced apoptosis in glioma cells. PloS one. 2012; 7:e38706.

48. Jakubowicz-Gil J, Langner E, Badziul D, Wertel I and Rzeski W. Apoptosis induction in human glioblastoma multiforme T98G cells upon temozolomide and quercetin treatment. Tumour biology. 2013; 34:2367-2378.

49. Acehan D, Jiang X, Morgan DG, Heuser JE, Wang X and Akey CW. Three-dimensional structure of the apoptosome: implications for assembly, procaspase-9 binding, and activation. Molecular cell. 2002; 9:423-432.

50. Deng Y, Lin Y and Wu X. TRAIL-induced apoptosis requires Bax-dependent mitochondrial release of Smac/ DIABLO. Genes \& development. 2002; 16:33-45.

51. Cartron PF, Loussouarn D, Campone M, Martin SA and Vallette FM. Prognostic impact of the expression/ phosphorylation of the $\mathrm{BH} 3$-only proteins of the BCL-2 family in glioblastoma multiforme. Cell death \& disease. 2012; 3:e421.

52. Kouri FM, Jensen SA and Stegh AH. The role of Bcl-2 family proteins in therapy responses of malignant astrocytic gliomas: Bcl2L12 and beyond. TheScientificWorldJournal. 2012; 2012:838916.

53. Taylor RC, Cullen SP and Martin SJ. Apoptosis: controlled demolition at the cellular level. Nature reviews Molecular cell biology. 2008; 9:231-241.

54. Chen L, Willis SN, Wei A, Smith BJ, Fletcher JI, Hinds MG, Colman PM, Day CL, Adams JM and Huang DC. Differential targeting of prosurvival Bcl-2 proteins by their BH3-only ligands allows complementary apoptotic function. Molecular cell. 2005; 17:393-403.

55. Gelinas $\mathrm{C}$ and White E. BH3-only proteins in control: specificity regulates MCL-1 and BAK-mediated apoptosis. Genes \& development. 2005; 19:1263-1268.

56. Webb J. (1963). Effect of more than one inhibitor, in Enzyme and Metabolic inhibitor. Academic Press. (New York, pp. 66-77, 487-512.

57. van Delft MF, Wei AH, Mason KD, Vandenberg CJ, Chen L, Czabotar PE, Willis SN, Scott CL, Day CL, Cory S, Adams JM, Roberts AW and Huang DC. The BH3 mimetic ABT737 targets selective Bcl-2 proteins and efficiently induces apoptosis via Bak/Bax if Mcl-1 is neutralized. Cancer cell. 2006; 10:389-399.

58. Zamaraev AV, Kopeina GS, Zhivotovsky B and Lavrik IN. Cell death controlling complexes and their potential therapeutic role. CMLS. 2015; 72:505-517.

59. Nicolaidis S. Biomarkers of glioblastoma multiforme. Metabolism: clinical and experimental. 2015; 64:S22-27.

60. Le Novere N. Quantitative and logic modelling of molecular and gene networks. Nature reviews Genetics. 2015; 16:146-158.

61. Fekete B, Werlenius K, Orndal C and Rydenhag B. Prognostic factors for glioblastoma patients - a clinical population-based study. Acta neurologica Scandinavica. 2015.

62. ElBanan MG, Amer AM, Zinn PO and Colen RR. Imaging genomics of Glioblastoma: state of the art bridge between genomics and neuroradiology. Neuroimaging clinics of North America. 2015; 25:141-153.

63. Knight MJ, Riffkin CD, Muscat AM, Ashley DM and Hawkins CJ. Analysis of FasL and TRAIL induced apoptosis pathways in glioma cells. Oncogene. 2001; 20:5789-5798.

64. Opel D, Westhoff MA, Bender A, Braun V, Debatin KM and Fulda S. Phosphatidylinositol 3-kinase inhibition broadly sensitizes glioblastoma cells to death receptor- and druginduced apoptosis. Cancer research. 2008; 68:6271-6280.

65. Hou W, Han J, Lu C, Goldstein LA and Rabinowich H. Enhancement of tumor-TRAIL susceptibility by modulation of autophagy. Autophagy. 2008; 4:940-943. 
66. Han J, Hou W, Goldstein LA, Lu C, Stolz DB, Yin XM and Rabinowich $\mathrm{H}$. Involvement of protective autophagy in TRAIL resistance of apoptosis-defective tumor cells. The Journal of biological chemistry. 2008; 283:19665-19677.

67. Fulda S. The dark side of TRAIL signaling. Cell death and differentiation. 2013; 20:845-846.

68. Zhang J, Stevens MF and Bradshaw TD. Temozolomide: mechanisms of action, repair and resistance. Current molecular pharmacology. 2012; 5:102-114.

69. Happo L, Strasser A and Cory S. BH3-only proteins in apoptosis at a glance. Journal of cell science. 2012; 125:1081-1087.

70. Deeks ED. Venetoclax: First Global Approval. Drugs. 2016; 76:979-987.

71. Gieffers C, Kluge M, Merz C, Sykora J, Thiemann M, Schaal R, Fischer C, Branschadel M, Abhari BA, Hohenberger P, Fulda S, Fricke H and Hill O. APG350 induces superior clustering of TRAIL receptors and shows therapeutic antitumor efficacy independent of cross-linking via Fcgamma receptors. Molecular cancer therapeutics. 2013; 12:2735-2747.

72. Seifert O, Plappert A, Fellermeier S, Siegemund M, Pfizenmaier K and Kontermann RE. Tetravalent antibodyscTRAIL fusion proteins with improved properties. Molecular cancer therapeutics. 2014; 13:101-111.

73. Wang J, Ma Y and Cooper MK. Cancer stem cells in glioma: challenges and opportunities. Translational cancer research. 2013; 2:429-441.

74. Lathia JD, Mack SC, Mulkearns-Hubert EE, Valentim CL and Rich JN. Cancer stem cells in glioblastoma. Genes \& development. 2015; 29:1203-1217.
75. Ortensi B, Setti M, Osti D and Pelicci G. Cancer stem cell contribution to glioblastoma invasiveness. Stem cell research \& therapy. 2013; 4:18.

76. Hetschko H, Voss V, Horn S, Seifert V, Prehn JH and Kogel D. Pharmacological inhibition of Bcl-2 family members reactivates TRAIL-induced apoptosis in malignant glioma. Journal of neuro-oncology. 2008; 86:265-272.

77. Rehm M, Huber HJ, Dussmann H and Prehn JH. Systems analysis of effector caspase activation and its control by $\mathrm{X}$-linked inhibitor of apoptosis protein. The EMBO journal. 2006; 25:4338-4349.

78. Laussmann MA, Passante E, Hellwig CT, Tomiczek B, Flanagan L, Prehn JH, Huber HJ and Rehm M. Proteasome inhibition can impair caspase-8 activation upon submaximal stimulation of apoptotic tumor necrosis factor-related apoptosis inducing ligand (TRAIL) signaling. The Journal of biological chemistry. 2012; 287:14402-14411.

79. Lindner AU, Concannon CG, Boukes GJ, Cannon MD, Llambi F, Ryan D, Boland K, Kehoe J, McNamara DA, Murray F, Kay EW, Hector S, Green DR, et al. Systems analysis of BCL2 protein family interactions establishes a model to predict responses to chemotherapy. Cancer research. 2013; 73:519-528.

80. HF K. The Application of Electronic Computers to Factor Analysis. Educational and Psychological Measurement. 1960; 20:141-151.

81. RB C. The Scree Test For The Number Of Factors. Multivariate Behavioral Research. 1966; 1:245-276.

82. RA F. The use of multiple measurements in taxonomic problems. Annals of human genetics 1936; 7:179-188. 